\title{
III
}

\section{THE PROBLEM OF THE DEFAULTER}

By A. D. FRAZER, M.B., Ch.B. (V.D. Medical Officer, County Borough of Dudley)

THE problem of the defaulting patient exercises the mind of every V.D. Medical Officer. Such a case constitutes a grave potential danger to himself and others, and reduces to naught the value of the time and treatment already expended on him. With a view to the possible removal of the cause of defection, the reasons given by fifty defaulters, who reported in answer to the routine letter sent in such cases, were analysed and the following results obtained :-

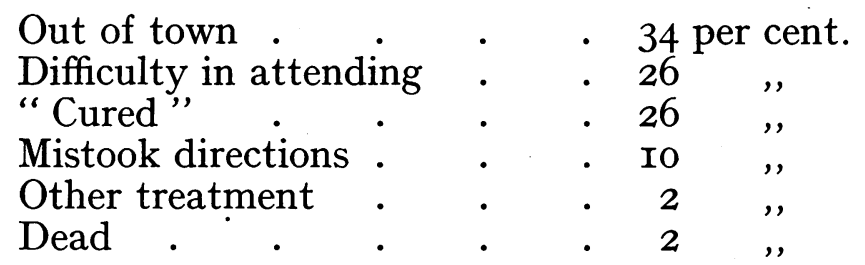

Out of Town.-Of the $\mathrm{I} 7$ cases comprising this heading, 5 were travelling pedlars and 3 commercial travellers. These men had been away on rounds taking one to three months, and as they felt well they thought it would be sufficient to report on return. The same reason was given by four men who had had temporary jobs in another town. Five others had removed to neighbouring villages and, but for the letter, would not have been seen again until the development of late specific lesions.

It is interesting to note that fifteen out of these seventeen cases were syphilitic, and all had had at least one course of treatment. The two gonococcal cases had no urethral discharge, but the urines were hazy.

Difficulty in Attending.-Four unemployed men had obtained work during the hours the clinic is open. A similar number of mothers who had brought their children regularly for about a year decided that, as nothing now seemed wrong, the expense of travel was too great (the expense varied between $8 d$. and Is. $6 d$. a week). Heavy 


\section{THE PROBLEM OF THE DEFAULTER}

expense was also pleaded by two adult males. The remaining three had had long illnesses (gastric ulcer, influenza and whooping cough).

"Cured."-This type of defaulter is the hardest to eradicate. When the discharge stops or the rash fades the idea of further attendance is scorned, and in a few years another resistant case applies for treatment.

Mistook Directions.-As all directions are repeated many times, it was rather staggering to find that ro per cent. of the defaulters gave this as the reason. For two men a note for dental treatment meant that the dentist would finish the treatment. A case of angina pectoris concluded that attendance both on his own doctor (for observation) and the clinic was a work of supererogation, and a fourth had put himself on a three months' rest. The last, on being told to report the following week for tests of cure, heard only the magic word " cure."

Other Treatment.-One patient had preferred private treatment to the publicity of the clinic.

Dead.--One case had died from intercurrent infection.

\section{Discussion}

Some of the percentages in this analysis may be too high for general application. The 2 per cent. defaulting from death certainly is, and the number "out of town" is due in part to the position of Dudley as the centre of a large industrial area. Again, there are other reasons given by defaulters which have not appeared in this outline-loss of hope in a long-treated Wassermann-fast case, a painful hip or an arm infiltration, or the fear of discovery by husband or wife.

Excluding children, the age of the defaulters varied between nineteen and sixty years. About half occurred in the age group 20-25 years, but as this corresponds to the age of the clinic's clientèle, no significance can be attached to it. Similarly, sex plays no part in causation.

On examination of the figures obtained, it is seen that 36 per cent. stayed away deliberately ( 26 per cent. thought they were cured and ro per cent. of those out of town did not intend to report). This section is very hard to convince, and all one can do is to repeat warnings of the danger of partial cure and continue the present propaganda work. The remaining 62 per cent. would attend 


\section{BRITISH JOURNAL OF VENEREAL DISEASES}

with slight encouragement. They are on the border line, and easily swayed. A small difficulty makes them default; smooth it away and they will attend again. If this were done the rate of defaulters might be lowered by almost two-thirds. For this reason we have decided to redouble our efforts at the Dudley clinic along the following lines :-

(I) Impress on all patients at intervals the necessity of treatment at other centres when unable to attend the original clinic.

(2) Rearrange the hours of clinics to suit all workers, and, if possible, give monetary aid for travel in necessitous cases.

(3) Multiply the warnings that treatment must be completed to ensure cure. The portrayal of a ghastly end must be avoided lest syphilophobia develops, but the advantages of a healthy life, free from worry of a relapse, will be impressed.

These warnings are especially necessary when the discharge of gonorrhœea has ceased, and between the ninth and twelve months of antisyphilitic treatment. Seventyfive per cent. of the defaulters ceased attending at these times.

(4) The patient will repeat all directions so that no misunderstanding can occur.

By these means we hope to diminish our rate of defaulters very substantially within the next twelve months. 